\title{
La construcción del orden político y las celebraciones republicanas en la Nueva Granada (Colombia, 1810-1832)
}

\section{Por Jorge Conde Calderón ${ }^{* *}$ y Edwin Monsalvo Mendoza}

\begin{abstract}
Resumen
Con la independencia y el establecimiento del régimen republicano, las ceremonias jugaron un papel importante en el proceso de construcción del Estado y de la Nación, ya que a través de ella con el empleo de un lenguaje político inédito y una simbología novedosa fueron colocadas en juego viejas y nuevas estrategias de dominación. Estos aspectos plantean la importancia de las ceremonias para un sistema político por cuanto refrendan las relaciones de poder y les proporcionan legitimidad.

Este trabajo se pregunta por el papel que desempeñaron las formas externas (o el protocolo) usadas en los actos públicos que marcan el tránsito del poder monárquico al republicano.
\end{abstract}

Palabras clave: Poder, orden político, celebraciones republicanas, juras constitucionales

\begin{abstract}
With independence and the establishment of the republican regime, ceremonies played an important role in the process of State building and Nation, since through it with the use of unprecedented political language and symbols were placed in new game old and new strategies of domination. These issues raise the importance of ceremonies for a political system as it endorses the power relations and provide legitimacy.

This work questions the role played by the external forms (or protocol) used in public events marking the transition from monarchical to the republican government.
\end{abstract}

Key words: Power, political power, republican celebrations, swear constitutional

\section{Introducción}

Desde los albores del proceso de independencia en Hispanoamérica la promulgación de constituciones se constituyó en factor preponderante. Ello estuvo relacionado con la adopción peculiar de un liberalismo que representó principalmente una experiencia a mitad de camino entre las sociedades del Antiguo Régimen y las sociedades individualistas modernas.

Las constituciones expedidas desde el mismo momento de la Independencia fueron juradas en los principales centros urbanos de la actual Colombia, en medio de celebraciones que constituían verdaderas fiestas cívicas. Los ceremoniales presentaron rasgos similares a los de las juras reales del período colonial. Aunque también introdujeron modificaciones con relación al ceremonial hispánico y plantearon nuevos valores políticos y culturales.

\footnotetext{
*Artículo Tipo 2: de reflexión según Colciencias

*** Historiador, profesor de la Universidad del Atlántico. Email: jorgecondecalderon@gmail.com

${ }^{* * * *}$ Historiador, profesor de la Universidad de Caldas. Email: edwinmonsalvo@gmail.com
} 
Durante el siglo XIX, las ceremonias jugaron un papel importante en el proceso de construcción del Estado y de la Nación, ya que en esta construcción la dominación simbólica fue trascendental por cuanto se ponían en juego viejas y nuevas estrategias de dominación. Como lo plantea E. P. Thompson: "Cada sociedad tiene su propio estilo de teatro; gran parte de la vida política de nuestras propias sociedades puede entenderse sólo como una contienda por la autoridad simbólica" (Thompson, 1979, p. 52).

En la sociedad colonial, el ceremonial era un medio para mantener el orden social; por eso era tan importante el orden de la procesión, la organización de las sillas, el orden del discurso o el turno de la palabra. Con el establecimiento del sistema republicano se reacomodaron las jerarquías sociales. Sin embargo, estas nuevas jerarquías impuestas a partir de las independencias, requirieron de un determinado comportamiento ritualizado que en alguna forma imitaba al del Antiguo Régimen (Garavaglia, 1996, p. 8).

Este trabajo analiza el papel político desempeñado por los rituales oficiados en medio de las celebraciones públicas o fiestas cívicas desplegadas entre el antiguo régimen y la nueva forma republicana de gobierno, las cuales fueron, además, actos oficiales que marcaron el tránsito del poder monárquico al republicano. El propósito consiste en mostrar cómo, a pesar de la adopción de formas republicanas de gobierno con su corolario, el sistema representativo ${ }^{1}$, en la Nueva Granada las fiestas cívicas no propiciaron un cambio radical en el imaginario político. Por el contrario, esos eventos relacionados con la proclamación de una Constitución o la aceptación de las nuevas autoridades presentaban rasgos similares a muchas de las ceremonias de sucesión al trono real durante el Antiguo Régimen. En primer lugar, describiremos las ceremonias de juras de la constitución de Cádiz en las provincias de la Nueva Granada, las cuales fueron las que conservaron en escena los rituales tradicionales del antiguo régimen, aunque empezaron a introducirse elementos nuevos como el de convocar a los vecinos con el titulo de ciudadanos. En un segundo plano, son analizadas las juras de algunas constituciones provinciales y las de 1821 y 1832, en las cuales aparecía reafirmada la forma republicana de gobierno. El análisis de esas celebraciones permite establecer las permanencias y los cambios en las prácticas políticas tendientes a la legitimación del poder y explicar el papel de la jura y la publicidad política en la sociedad republicana. Es necesario señalar que en la realización de en la realización de los homenajes a las constituciones eran convocados los ciudadanos, quienes realizaban los actos de juras ordenados y dispuestos como cuerpos a la manera del Antiguo Régimen. Ello también intenta ser analizado desde la dimensión de su impacto político, en unas sociedades cuyos valores seguían siendo tradicionales.

Lo planteado tiene como fundamento la noción de que la fiesta consistía en una relación social entre varios actores, los cuales expresaban conductas festivas en el espacio público. Al hacerlo, los actores experimentan gratificaciones

\footnotetext{
${ }^{1}$ Lo que significa un cambio en los mecanismos de legitimidad del poder político que pasan de la tradición y la herencia (propios de la monarquía) al ejercicio electoral a través del cual los individuos eligen a sus mandatarios,
} 
inmediatas. Ellas también constituyen actos expresivos de la más intensa comunicación que contribuyeron a crear nuevas relaciones sociales y permitieron el surgimiento de una nueva realidad pública. Desde un principio, las fiestas cívicas republicanas fueron manifestaciones de carácter público cuyo objetivo principal consistía en representar alegóricamente diversos momentos de la unidad indisoluble entre los nuevos súbditos, ahora representados por los ciudadanos, y la nación cuyo cuerpo indivisible y soberano reposaba en la constitución.

Los gobiernos republicanos organizaban tres clases de conmemoraciones 0 fiestas: las de jura de la constitución, las cívicas electorales y las patrióticas. Todas incorporaron la religiosidad y las manifestaciones festivas populares al proceso de invención de la tradición cívico republicana, en la cual se enlazaban el patriotismo constitucional y una religión civil representados en un universo simbólico generador de un orden que aseguraba un vínculo constitutivo entre el individuo y la sociedad ${ }^{2}$. Ese universo tuvo en los rituales y ceremoniales su expresión concreta constituyéndose en un teatro del poder de utilidad permanente para la difusión de los valores republicanos. Esto era facilitado porque constituían manifestaciones de carácter público realizadas en la plaza y a la vista de los ojos del pueblo allí congregado, en las cuales se ligaba a cada uno de los ciudadanos, por más poderoso que éste fuera, con el presidente de la republica y sus ministros, con el obispo y con los otros individuos que ocupaban las magistraturas más relevantes (Garavaglia, 1996, p. 11) .

Las juras constitucionales fueron inauguradas con las constituciones provinciales durante el período de la Primera República (1810-1815), las cuales coincidieron en alguna provincias neogranadinas con la jura de la Constitución de Cádiz, y prolongadas con las constituciones republicanas entre 1821 y 1832, las cuales estaban consagradas en sus primeros artículos, en medio de las inconsistencias semánticas de la época, en cuanto a los significados de los términos Estado y Nación.

\section{"Jurais ante Dios..." Las cortes de Cádiz y la transición del antiguo régimen}

El 2 de julio de 1808, José María de Lizarralde, interventor encargado de la administración de tabacos de Pore (Casanare), informaba que el mes anterior había cumplido con el real decreto que le ordenaba "jurar fidelidad y vasallaje al nuevo monarca" Fernando VII (AGN, 1808, rollo 4, f. 387). Como José María, todas las autoridades del Nuevo Reino de Granada habían recibido las noticias de los sucesos de Madrid, y sabían que el "rey deseado" había asumido el poder real y que por lo tanto, todos "los pueblos" de la monarquía debían jurar

\footnotetext{
${ }^{2}$ Para un desarrollo de aspectos concernientes a la religión civil y su relación con el patriotismo constitucional, véase, Josetxo Beriain, "La construcción de la identidad colectiva en las sociedades modernas", en, Josetxo Beriain y Patxi Lanceros, comps. Identidades culturales, Bilbao, Universidad de Deusto, 1996, p. 37

${ }^{3}$ Para lo de tradiciones inventadas, véase, Eric Hobsbawn and Terence Ranger, eds., The Invention of Tradition, Cambridge University Press, Canto edition, 1992. Una traducción al español de la introducción realizada por Eric Hobsbawn está publicada en, Historias, 19, 1988, pp. 3-15. Un estudio amplio y general sobre la teatralidad de poder es el de, Georges Balandier, El poder en escenas, Barcelona, Ediciones Paidós, 1994.
} 
lealtad al nuevo monarca. En Santa Fe de Bogotá, la jura se realizó durante la tarde del domingo 11 de septiembre y el ritual fue igual al de las ceremonias tradicionales de sucesión: se instalaron arcos triunfales en las plazuelas de San Francisco y San Agustín, se acuñaron monedas conmemorativas que luego fueron arrojadas al público, se introdujo el retrato del monarca en la galería del ayuntamiento, se realizó una cabalgata de acompañamiento del real pendón, se levantó el tablado con dosel para la ceremonia de juramento y hubo bebidas de cierre en la casa de uno de los alcaldes ordinarios. Esta fue la ceremonia pública, a la cual asistieron todos los vecinos de la capital virreinal (BNC, 1808, 317). Pasado este día se realizó una misa de acción de gracias en la Catedral. En los meses siguientes la ceremonia se repetiría en Popayán y Lima. Sin embargo, en Cartagena la jura fue celebrada en una fecha anterior a la de Bogotá, el 9 de agosto de 1808 después de las fiestas del 22 y 23 de junio con motivo del ascenso al trono del príncipe de Asturias (Martínez, 2005).

Este ritual se repetiría incansablemente en los años siguientes. Sin embargo, la abdicación y captura del rey por los franceses dio inicio a una serie de acontecimientos como la conformación de las juntas de gobierno y movimientos independentistas, los cuales originaron la multiplicación de la soberanía. Cada ciudad, villa o lugar se sintió con los derechos y fueros fundamentales para invocar o proclamar su soberanía. Es decir, el poder soberano que asistía a los pueblos ante la ausencia del monarca. Los derechos esgrimidos eran corporativos y remitían a los tradicionales fueros y privilegios que tenían su fundamento en el jusnaturalismo español y las doctrinas moderadas de algunos estudiosos del siglo XVIII. En medio de estos hechos, surgió la necesidad de ordenar y regular el "cuerpo social" a través de un conjunto de normas que contenían los principales derechos y deberes de los ciudadanos. Con su materialización en una carta constitucional, las ceremonias reaparecieron ya no para celebrar la sucesión al trono real sino para proclamar y jurar la nueva constitución 0 , en otros casos, solemnizar la posesión de un mandatario elegido por el pueblo.

El punto de partida de ese constitucionalismo fue la deliberación de las Cortes de Cádiz, consideradas por los contemporáneos como la expresión del liberalismo en el mundo hispánico. Una de las imágenes que ha quedado de la sesión en la cual se aprobó y promulgó la Constitución gaditana en el mes de marzo de 1812 muestra a los diputados, incluso a los liberales católicos españoles, jurando ante los evangelios mientras un representante de la iglesia sostiene el documento y otro lee la jura.

Aunque se afirma mucho sobre el aparente reformismo de las Cortes, estas no desarrollaron una estrategia para generar un nuevo imaginario político. Por el contrario recurrieron al imaginario tradicional para imponer el nuevo orden político. De esa manera, conservaron en el imaginario de la época referencias específicas a un vasto sistema simbólico generado por toda la colectividad y a través del cual ella "se percibe, se divide y elabora sus finalidades". Por consiguiente, a través de su imaginario social, la colectividad construía su identidad elaborando una representación de sí misma; marcaba la distribución de los papeles y las posiciones sociales; expresaba e imponía ciertas creencias comunes, fijando especialmente modelos formadores como el del "jefe", el del "buen súbdito", el del "valiente guerrero", el de "ciudadano", el del "militante", 
etc. Así, es producida una representación totalizante de la sociedad como un "orden", según el cual cada elemento tiene su lugar, su identidad y su razón de ser. De este modo, el imaginario social era una de las fuerzas reguladoras de la vida colectiva. Al igual que las demás referencias simbólicas, los imaginarios sociales no indicaban solamente a los individuos su pertenencia a una misma sociedad, sino que también definían los medios inteligibles de sus relaciones con ésta, con sus divisiones internas y con sus instituciones (Backo, 1991, p. 28).

Por otro lado, en la política moderna, la construcción del imaginario político requiere un nivel de secularización lo suficientemente marcado como para garantizar que el cambio de los valores sea visible de por sí. En este sentido, ni la Constitución de Cádiz, ni las provinciales de la Nueva Granada, reivindicaron la secularización, utilizando imágenes y rituales del pasado expresados ahora con un nuevo vocabulario -o algunas veces también con palabras del vocabulario antiguo adecuadas a la nueva realidad.

La misma carta de Cádiz de 1812 estableció que todos los pueblos que pertenecían a la monarquía española debían hacer la publicación y el juramento del texto. Ambas ceremonias pertenecían al imaginario político del Antiguo Régimen. La publicación era el ritual por medio del cual el rey hacía una pública representación de su dominio, como algo superior frente a sus súbditos, y como algo bien diferente de lo que se considera la esfera pública moderna (Annino, 1995, p. 285). Según las Cortes, la publicación debía hacerse en todos los pueblos del reino por los jefes municipales o jueces de cada pueblo. El ayuntamiento debía señalar el día de la publicación solemne de la carta

... mientras en los lugares más públicos se deberían leer en alta voz toda la Constitución y el mandamiento de la Regencia que obligaba a cumplirla. Esta ceremonia estaría acompañada del repique de las campanas, iluminación y salvas de artillería (ACDM, 1812, leg. 29) ${ }^{4}$.

El primer día festivo inmediato a la publicación se debían reunir los vecinos en su respectiva parroquia, asistiendo el juez y el ayuntamiento para celebrar una misa solemne de acción de gracias. Ante este público también "se leerá la constitución antes del ofertorio, se hará por el cura párroco, o por el que este designe, una breve exhortación correspondiente al objeto, después de concluida la misa, se prestará juramento por todos los vecinos y el clero de guardar la constitución". El decreto fue enviado a todas las provincias españolas peninsulares y las americanas que inmediatamente después de recibir la carta y la orden, iniciaron las ceremonias. Una de las más tempranas fue la de San Felipe de Portobelo de la cual daba cuenta el secretario de las cortes en los siguientes términos:

\footnotetext{
${ }^{4}$ Sin embargo, el 23 de mayo las mismas cortes decretan que la jura del pueblo y el clero deben ser sin preferencia alguna y en una sola voz. Joaquín de Mosquera y Figueroa, presidente, Juan Villavicencio, Ignacio Rodríguez de Rivas, el conde de Abismal. Decreto en que se fixa el modo con que el clero y el pueblo han de jurar la constitución política en toda la monarquía. Cádiz 23 de mayo de 1812”, Leg. 29, Expte. 1.
} 
El virrey del Nuevo Reino de Granada en carta de 31 de octubre de 1812, numero 41, me ha remitido los adjuntos testimonios que paso a manos de V. S. de orden de la Regencia del Reyno, relación de haberse publicado y jurado la constitución política de la monarquía por el ayuntamiento, pueblo y clero de la villa de los santos, y por el gobernador, ayuntamiento, pueblo y clero de la ciudad de San Felipe en Portovelo, y por el gobernador, ayuntamiento, pueblo y clero en la ciudad de Santiago en Veragua (ACDM, 1813, leg. 29, exp. 1).

Como se puede apreciar, en la ceremonia participaban todas las autoridades civiles y eclesiásticas. A estas últimas les correspondía presidir la ceremonia y recibir el juramento de las civiles. Hasta este punto se habían cumplido las dos ceremonias de la Constitución, su publicación y juramento. En la mañana, en presencia del pueblo reunido, el texto de la constitución, representado como cuerpo político, era llevado como el Santo Sacramento (Demelas, p. 179). Luego se realizaban otros actos que engalanaban las festividades; por ejemplo, el decreto del 18 de marzo también establecía que los tribunales de cualquier clase, "justicias, virreyes, capitanes generales, gobernadores, juntas provinciales, ayuntamientos, M. RR. Arzobispos, RR. Obispos, Prelados, Cabildos eclesiásticos, Universidades, Comunidades religiosas, y todas las demás corporaciones y oficinas de todo el reyno", así como las catedrales, colegiatas, universidades y comunidades religiosas deberían celebrar una misa de acción de gracias con Te Deum, después de haber jurado los respectivos Cabildos y comunidades la Constitución. Al día siguiente de la publicación se debían liberar a los presos por delitos que no merecieran pena corporal (ACDM, 1812, leg. 29, exp. 1).

¿A qué se referían las cortes con tribunales y corporaciones? Aunque a través del decreto citado se perciben intentos de las cortes de acabar con los privilegios, en la práctica fueron prudentes y mantuvieron la idea generalizada como la sociedad estaba constituida por cuerpos y corporaciones, estamentos ante los cuales podía legitimarse la carta de $1812^{5}$.

Otro documento ofrece una respuesta más pertinente al problema planteado. El 16 de abril de 1813, en las sesiones secretas de las cortes reunidas en la iglesia de San Felipe Neri fue leído un informe del Tribunal de la Inquisición de Cartagena de Indias con el cual se informaba haber publicado y jurado la Constitución de Cádiz (ACDM, 16 de abril de 1813, leg. 29, exp. 1). Paradójicamente, mientras el cabildo, los notables y constituyentes cartageneros habían promulgado su propia constitución el año anterior y esta ciudad se enfrentaba a Santa Marta por ser un bastión de los realistas, el Tribunal de la Inquisición juraba la carta gaditana, y más paradójico aún por el hecho de que en el mismo año, los diputados de las cortes habían decretado eliminar estos tribunales.

Sin embargo, es importante resaltar que, a pesar de que la Constitución había borrado los cuerpos, tal como se estableció en el decreto de 23 de mayo de 1812, fue el Cuerpo del Santo Oficio el encargado de llevar a cabo esta jura.

\footnotetext{
${ }^{5}$ En todo caso este es un período donde los lenguajes políticos suelen ser ambiguos y los términos polisémicos. Véase, José Carlos Chiaramonte, Nación y Estado en Iberoamérica, Buenos Aires, Editorial Sudamericana, 2004. También del mismo autor: Ciudades, provincias, estados: orígenes de la nación argentina (1800-1846), Buenos Aires, Ariel, 1997.
} 
Quizás, el peligro externo, el enfrentamiento faccioso interno y la crisis política en que estaba sumida la junta de gobierno de Cartagena, lo cual había sido reconocido por las cortes en sus sesiones secretas desde el 16 de julio de 1811, le permitió a la Inquisición asumir el papel de garante y poder legitimador de la constitución gaditana. Pero el caso de Cartagena no fue el único. En la sesión pública del 25 de mayo de 1813 se leyó en la misma corte el siguiente informe proveniente de gobernador de Riohacha, que junto a Santa Marta mantenía fidelidad al rey en la costa Caribe colombiana:

De orden de la regencia del reyno remito a ustedes el adjunto certificado de haberse publicado y jurado la constitución política de la monarquía española en la ciudad del Río de el Hacha, en el Nuevo Reyno de Granada, por el gobernador comandante general de aquella plaza y su guarnición, por su ayuntamiento, pueblo y clero, y por las cabezas de los sitios de la provincia (ACDM, 24 de mayo de 1813, leg. 29, exp. 1).

El lenguaje utilizado en esta jura fue el mismo que en la de Cartagena, y más evidente aún que en la de esta última, en Riohacha los cuerpos se representaban en orden jerárquico. La guarnición apareció al lado del gobernador; tal vez esto se debió a la creciente importancia que habían asumido las milicias en el contexto de la guerra y la necesidad de la autoridad provincial de asegurarse su lealtad. Como podemos observar por las juras del Tribunal de la Inquisición de Cartagena y la de Riohacha, más de un año después de la promulgación de la Constitución de Cádiz, aún en los reinos de la monarquía española se estaba cumpliendo la ceremonia de publicación y juramento. Al respecto Federica Morelli, estudiosa de la transición del Antiguo Régimen a la política moderna señala que aún con la promulgación de la Constitución, las prácticas políticas no variaron, debido a la fuerza de la tradición y a que las mismas Cortes vincularon la Constitución a la religión católica. Por lo tanto, concluye la historiadora italiana, "no se asiste en América hispana a un proceso de secularización de la obligación política, a causa de la naturaleza percibida como esencialmente contractual del juramento. Lo sacro, la divinidad, constituían la garantía metapolítica del pacto, la cual hallaba su expresión no solo en una cultura o en una ideología, sino también en la iglesia como institución" (Morelli, 2005, p. 103).

La presencia del obispo reforzaba la relación simbólica del poder civil con el religioso a través de la costumbre del Te Deum. Al respecto, un visitante extranjero comentaba: "El primer día de navidad se cantaba el Te Deum en acción de gracias por la liberación del suelo de la república de sus enemigos" (Cochrane, 1994, p. 236). Tal vez, ello obedeció al deseo de los criollos de desterrar de malos espíritus y fuerzas malignas el lugar donde iba a instalarse la república.

En otro acto de aparente intimidad social, pero igualmente público, era puesta en escena la misma relación. En la Santa Iglesia Catedral de Cartagena, el Venerable Deán Juan Marimon y Enríquez, durante la misa solemne pronunció un discurso "para implorar del altísimo el acierto de las elecciones" de los representantes para la convención granadina de 1831. El canónigo, como miembro de la asamblea electoral, reconocía que ello era producto de la libre 
voluntad del pueblo, pero imploraba a los ciudadanos por la escogencia de electores

...que conozcan a fondo toda la Nueva Granada, sus hábitos, sus poblaciones, sus ejercicios, sus inclinaciones y que tengan también un vasto conocimiento de Venezuela y del Ecuador: porque aunque la Constitución que se trata de hacer debe ser puramente granadina, es preciso, sin embargo que sea homogénea con las otras para no formar una sociedad monstruosa; y que se le dejen sus proporciones, y si se puede decir así, sus ensambles, para que de las tres se forme el pacto social que uno de los tres departamentos que deben conservar la representación nacional colombiana, porque sin esta unión perecerá enteramente la República (Gaceta de Cartagena, 24 de julio de 1831, $\mathrm{n}^{\circ}$ 500).

La relación estrecha entre lo civil y lo religioso adquiría su mayor reconocimiento como teatro del poder con la jura de la constitución. Un acto de duplicación simbólica que evocaba el ceremonial de los "dos cuerpos del Rey" (Kantorowicz, 1985).

\section{Las celebraciones republicanas}

Durante la Primera República se organizaron diversas clases de conmemoraciones o fiestas patrióticas. Las de mayor trascendencia fueron las cívicas y las de jura de la constitución. Todas incorporaron la religiosidad y las manifestaciones festivas populares al proceso de invención de la tradición cívico republicana, en la cual se enlazaban el patriotismo constitucional y una religión civil representados en un universo simbólico generador del nuevo orden que aseguraba un vínculo constitutivo entre el individuo y la sociedad.

Ese universo tuvo en los rituales y ceremoniales su expresión concreta constituyéndose en un teatro del poder de utilidad permanente para la difusión de los valores republicanos porque constituían manifestaciones de carácter público realizadas en la plaza y a la vista de los ojos del pueblo allí congregado. En ellos se involucraba a todos y cada uno los ciudadanos, por más poderoso que éste fuera, con el presidente de la Junta Suprema, el estado soberano respectivo, con el obispo y con los otros individuos que ocupaban las magistraturas más relevantes.

Las fiestas cívicas presentaban un carácter doméstico. Las primeras se llevaron a cabo en los días siguientes a la instalación de las Juntas Supremas de Gobierno. Eran anunciadas por bando público para una fecha, siempre un domingo, cuando se consideraba que había pasado la agitación y el tumulto. Una comisión presidida por el presidente de la Junta Suprema y una diputación nombrada al respecto se encargaba de su organización. En el mismo bando se les recordaba a los vecinos que para el primer acto debían concurrir a la iglesia e iluminar sus casas en aquella noche y la siguiente. De esta manera, por ejemplo, la Junta Suprema de la Provincia de Cartagena de Indias instalada el 13 de agosto de 1810 dio inicio a las celebraciones con los actos solemnes de gracias al Ser Supremo, repique de las campanas, estruendo de la artillería y de la música, como preliminares de una fiesta que sirvió para que el "Pueblo de 
todas clases" manifestara "sus nobles y patrióticos sentimientos" (Extraordinario de las Noticias, 29 de agosto de 1810, $n^{\circ} 140$ ).

En general, el día señalado los miembros de la Junta con el presidente a la cabeza, se dirigía por entre las filas de la tropa recibiendo honores y aclamaciones "de un inmenso Pueblo", hasta la puerta de la iglesia. Allí el obispo los recibía lanzándoles agua bendita y haciéndoles besar la cruz a él y a los jefes de los cuerpos. Luego de su ingreso al recinto sagrado se colocaba cerca del presbiterio, en su orden, el presidente en el medio frente al altar con los capellanes, ayudantes y la guardia de honor con su comandante. El obispo pronunciaba la oración respectiva, en la que no faltaban las invocaciones patrióticas, y el vocal representante del pueblo en la Junta su discurso en el cual deslizaba frases y sentencias bíblicas. Finalizada la misa se cantaba el solemne Te Deum. El repique de campanas y el estruendo de tres descargas de artillería anunciaban la clausura de este primer acto. A continuación, la Junta y los otros cuerpos civiles y militares regresaban con la misma solemnidad a la casa de gobierno, mientras las "gentes de ambos sexos, de todas clases y estados" paseaban por la plaza y calles adyacentes, comentando y charlando sobre diversidad de temas, en medio de la música militar ofrecida por los diferentes cuerpos de la guarnición.

Similares solemnidades eran cumplidas cuando se instalaban los cuerpos constituyentes, el Congreso de las provincias unidas o los cuerpos legislativos de los estados soberanos. A fines de 1810 fue instalado, en la ciudad de Bogotá, el Congreso de provincias unidas, un proyecto que no prosperó por cuanto no estuvieron los representantes de todas las provincias. Inicialmente, el 21 diciembre, a través de bando se anunció que éste se iba a instalar. Al día siguiente, la instalación era anunciada con descargas de artillería. En el tercer día se oficiaba misa de gracia, con asistencia de toda la junta de Bogotá y apenas los diputados de siete provincias. Luego, el presidente del congreso, Bernardo Álvarez, diputado de la provincia de Cundinamarca, recibía todos los honores como un Virrey, nuevamente aquí el poder en escena, otra vez salvas de artillería; en la tarde brindis en el palacio de gobierno, corrida de toros y durante tres noches seguidas, iluminación de las casas y sus balcones (Caballero, 1974, p. 73).

Cabe anotar que las corridas de toros estuvieron entre las prohibiciones ordenadas por los monarcas españoles. Sin embargo, siguieron siendo organizadas y celebradas por los gremios y corporaciones de artesanos. Este hecho proporciona elementos para formarnos la idea de que los sectores populares no estuvieron ausentes de festividades, celebraciones y conmemoraciones religiosas y cívicas y que su participación incluía rituales tradicionales.

En lo relativo al congreso, éste tuvo una pausa debido a las festividades de fin de año. Su receso transitorio también fue celebrado con composiciones musicales en honor a don Bernardo Álvarez, por el batallón de Guardias nacionales. En la noche, dos ninfas preciosamente vestidas portando el vítor (estandarte vencedor) pasearon por la plaza y las calles, en carro triunfal, con 
muchas luces producidas por fuegos artificiales, y acompañadas de toda la oficialidad.

Las juras constitucionales fueron inauguradas con la Constitución de Cundinamarca el 4 de abril de 1811. En las juras de la constitución también participaban las autoridades civiles, las tropas, el pueblo y el clero. Los funcionarios municipales se encargaban de la preparación de la fiesta, la decoración de la plaza en donde se llevaría a cabo la juramentación, y la organización de los actos de clausura durante los tres días de las celebraciones. En la organización participaban los vecinos. Hombres y mujeres eran comisionados para la realización de diversas tareas. Entre las principales estaban la limpieza de la ciudad y la iluminación de los balcones y ventanas que daban a las calles. Las diversiones públicas también eran variadas.

El día del juramento de la constitución, contados ejemplares de la constitución eran repartidos entre el público y se leían en voz alta aquellos artículos consagrados a los derechos y deberes del ciudadano. Además de la lectura realizada en la plaza pública, ésta se repetía durante varias semanas en la misa dominical. Después de cada una de ellas, el cura hacía una exhortación de la bondad del texto y recordaba el deber cristiano de obedecer. De tal manera que los rituales cívicos, políticos y religiosos que acompañaban las ceremonias de publicación y juramento fueron aprovechados para enseñar a los ciudadanos y feligreses los valores del nuevo texto, así como también sus deberes y derechos ${ }^{6}$.

Un capítulo especial merece el Acta Federal de las Provincias Unidas, ya que a pesar de las limitaciones constitucionales y judiciales de este texto para lograr una centralización efectiva del poder, ella fue acogida en los pueblos con celebraciones y juramentos públicos, lo cual puede considerarse, en parte, como una superación del provincialismo predominante en el período. También, porque empezaba a generalizarse la pertenencia a una comunidad mayor, ya fuera llamada la Nación, el Estado o la República. Aún más, el Acta, en su intento de homogeneizar el calendario festivo, consagró el 20 de julio de 1810 como la fecha en que se inició la transformación política de la Nueva Granada. En lo sucesivo, en algunos lugares del territorio neogranadino a través de bando comenzó a ser anunciada esa fecha como el año de la revolución (Pombo y Guerra, 1951, p. 224).

Otro evento que estuvo revestido de toda la pompa festiva fue la instalación del Colegio electoral. En el día indicado para tal efecto, sus integrantes, presididos por su presidente, iban de la sala de sesiones a la catedral a la misa del Espíritu Santo, celebrada por el señor provisor, el canónigo de mayor jerarquía, pero predicada por un capellán. Allí se exhortaba a los señores del colegio para que fuera acertado su elección y su comportamiento una vez concluida la función. Luego, regresaban a la casa electoral, y esperaban hasta el mediodía, cuando por bando eran convocados todos los cuerpos legislativos para prestar el juramento ante los señores del colegio.

\footnotetext{
${ }^{6}$ Seguimos la crónica invaluable de un contemporáneo de los eventos como José María Caballero
} 
Allí, acudían todos los cuerpos legislativos y prestaban el juramento. Por la tarde, se presentaban los regimientos en la plaza, con banderas, y juraban defender la patria y la religión hasta dar la última gota de sangre. El orden para prestar juramento era: primero, los oficiales de Milicias, quienes luego de jurar esperaban dos descargas de artillería y se retiraban. Seguían, los Nacionales, los cabos y sargentos de Milicias y los Patriotas, la compañía de Granaderos, y por último las milicias de infantería. Todas las compañías marchaban alrededor de la plaza, tocando dianas y dando vivas a la República. La fiesta de toros no faltaba y en la noche se celebraba con músicas y cantos patrióticos.

La celebración se extendía por tres noches consecutivas, en obsequio de la instalación del colegio electoral y elección del presidente de Estado. En una de las numerosas conmemoraciones cívicas y patrióticas, en Santafé de Bogotá, el cuerpo de sargentos y cabos de Milicias marchando, al compás de una famosa melodía, desde el cuartel con hachas de cera, aproximadamente 200 según un cronista de la época, y en medio de un farol de vara en cuadro, a una altura visible para todos los concurrentes, llevaban, por un lado, las armas de Cundinamarca y por el otro una flor de lis, como símbolo distintivo del regimiento. Por un tercer lado, una corona con una palma y una espada atravesada; por el frente una octava que, citando figuras mitológicas griegas, hacía alusión al presidente del estado y del colegio electoral, algunas veces la misma persona, y deseaba existencia eterna al gobierno (Caballero, 1974, pp. $85-86)$.

Las fiestas de jura de la constitución, celebradas con motivo de la promulgación de una nueva carta constitucional, adquirieron en algunas ocasiones un carácter electoral. Principalmente porque ellas eran promulgadas por los actores civiles y militares victoriosos luego de guerras civiles o golpes de estado. Se convocaban entonces elecciones para organizar un cuerpo constituyente o recomponer el congreso. Ese cuerpo se encargaba de legitimar el poder alcanzado por la fuerza. Así ocurrió con los textos constitucionales de 1821, resultado de la guerra independentista y promulgada sin que aquella todavía finalizara; la de 1832, creada luego de la disolución de la Gran Colombia, el golpe del general venezolano Rafael Urdaneta y la guerra de 1831, y con la cual comenzó su vida constitucional la República de la Nueva Granada.

En las juras de la constitución participaban las autoridades civiles, las tropas, el pueblo y el clero. Los funcionarios municipales se encargaban de la preparación de la fiesta, la decoración de la plaza en donde se llevaría a cabo la juramentación, y la organización de los actos de clausura durante cada uno de los tres días en que transcurrían las celebraciones. En las actividades de preparación participaban los vecinos. Hombres y mujeres eran comisionados para la realización de diversas tareas. Entre las principales estaban la limpieza de la ciudad y la iluminación de los balcones y ventanas que daban a las calles. Las diversiones públicas también eran variadas.

De importancia excepcional fue la promulgación de la Constitución de 1821. Los ceremonias y rituales que rodearon su juramentación eran magnificentes e imponentes, ya que se consideraba que con ella comenzaba de manera firme y 
definitiva el régimen republicano y se establecían las bases fundamentales para la organización estatal del territorio grancolombiano.

En Cartagena, mediante bando fue anunciada su promulgación con los respectivos tres días de festejos. Para la ocasión, la plaza de armas comprendida entre las parroquias de San Francisco y San Toribio fue organizada con tres tablados en forma de castillos. El primer día, 7 de enero de 1822, en el estrado principal, en donde tremolaba el pabellón tricolor, fueron ubicados el Intendente, quién presidía la municipalidad, el cabildo eclesiástico, todas las corporaciones y oficiales. A las cuatro de la tarde se dirigieron al palacio de gobierno, lugar destinado para la juramentación, la cual era realizada siguiendo una fórmula prescrita y común a todos. En ella, la máxima autoridad política del lugar tomaba en sus manos el libro de los Santos Evangelios junto con una imagen de Cristo crucificado y poniéndose en pie y en voz alta decía:

¿Juráis por Dios nuestro Señor y los Santos Evangelios cumplir y sostener la constitución de la República decretada? A que contestan sí juro y se respondía: si así lo hicieres Dios os ayude y sino El y la patria os lo demande.

De inmediato se hacía sonar una "armoniosa música militar". Concluida la juramentación se arrojaban "monedas corrientes, por no haber tiempo ni cuño para monedar otras alusivas al objeto". Luego comenzaban las "descargas de los cuerpos, los repiques de las campanas y triples salvas de artillería en todas las murallas"

En la noche, se iluminaban balcones y ventanas de las calles con lo cual "cada ciudadano rivalizaba á su vecino en las colgaduras y cristales". En medio de esa pompa resplandeciente se erigía imponente el Palacio de la Intendencia, "iluminado con más de mil luces colocadas simétricamente". En ellas, un "magnífico fresco", en pintura dentro de columnas de estilo toscano, aparecía la Diosa Astrea con la espada desenvainada, y en su pedestal inscrita la estrofa: "La Constitución jurada/Prometo que sostendré/Y por ello mantendré/Siempre desnuda la espada/l". Esta representación entusiasta de la antigüedad buscaba establecer un sólido vínculo de identificación entre los republicanos antiguos y los modernos (Schama, 1990, p. 182).

Un segundo fresco representaba al genio de la Libertad, con los emblemas del despotismo y tiranía pisados, y otra redondilla que indicaba los principios que sostienen a un gobierno convencional: "La sagrada Libertad se sostiene con la unión, valor, firmeza, igualdad, justicia y Constitución". En el medio de los dos cuadros estaban colocados los retratos de el presidente Libertador de la República Simón Bolívar y benemérito Vicepresidente General de División, Francisco de Paula Santander, "bajo un pabellón de damasco carmesí, con la Constitución por delante, simbolizando que por su imperio regían los pueblos".

\footnotetext{
${ }^{7}$ Seguimos la narración que trae Manuel Ezequiel Corrales en su compilación documental, la cual reproduce lo que reseñó la Gaceta de Cartagena de Colombia, Enero 13 de 1822, n ${ }^{0} 3$. Véase, Manuel Ezequiel Corrales, Efemérides y anales del Estado de Bolívar, Bogotá, Casa editora de J. J. Pérez. 1889, tomo II, p. 296.
} 
Las celebraciones del segundo día comenzaron con una misa cantada, un "panegírico" del gobernador del obispado Anastasio García de Frías y la toma de juramento convenido por el Soberano Congreso al Intendente del Departamento, el Comandante General Juan Salvador Narváez.

El mismo ritual era repetido seguidamente por las demás autoridades y corporaciones ante el Intendente, "quien lo tomo del numeroso pueblo que concurrió al acto, y del clero secular y regular el Gobernador del Obispado". Luego se entonaba el Te deum y se concluía con repiques de campana y salvas de artillería. Al tercer día desfilaron en orden de batalla los mismos cuerpos del primer día: brigada de artillería, batallones $1^{\circ}$ de Antioquia, Girardot, Alto Magdalena, Escuadrón de Guías del Estado Mayor, excepto la Compañía de Marina, se recibió juramento y mandó hacer fuego por batallones y triples saludos. En la noche, como en los días anteriores, se celebraban bailes públicos en la plaza de armas, en un salón iluminado. También en el palacio de gobierno se celebraba un baile por el Intendente festejando el juramento de las tropas. Hacia la medianoche y al frente de la Torre de la catedral se encendía un castillo de fuego de "donde bajó la estatua ardiente del inicuo virrey Sámano". En medio de este acto, los ciudadanos "poseídos de júbilo" por el "placer de considerar á sus ínclitos libertadores", y a ellos mismos "libres de una degradante esclavitud", aclamaban a cada instante con repetidas voces: "¡Viva la República! ¡Viva la Constitución! ¡Vivan nuestros Libertadores!” (Corrales, 1889, p. 297).

Otras festividades republicanas con la impronta nacional fueron las celebraciones de los aniversarios de las batallas de Boyacá, Junín, Ayacucho, de la entrada en Cartagena y Barranquilla del ejército libertador y la bendición de las banderas del Batallón Paya (Corrales, 1889, p. 295 y p. 329). Aunque fueron festejos destinados a reavivar el patriotismo de los ciudadanos, señalaban la dimensión creciente de la conmemoración militar y la fuerza armada en el proyecto de nación de los notables. Sin embargo, en un hecho tal vez paradójico, con el devenir de los años y la creencia de que la república se encontraba en proceso de consolidación, las celebraciones patrióticas locales comenzaron a competir con las fiestas republicanas que aparecían revestidas de un carácter nacional. El hecho era resultado de las grandes diferencias sociales, culturales y políticas existentes en el territorio de la república neogranadina y del cuestionamiento del proyecto homogeneizador de nación imaginado por los notables. Aún más, colocaba en el centro del proceso de construcción de la nación el conflicto entre el Estado nacional y la memoria étnica, entre el Estado nacional y las identidades locales y grupales ${ }^{8}$. Elemento presente, por ejemplo, durante la jura de la Constitución de 1832 cuando de manera simultánea el "consejo municipal" de Cartagena acordaba la iluminación de la Casa Consistorial durante dos noches seguidas, "en recuerdo del 11 de nove. en que se efectuo nuestra independencia" (BLAA, Fondo Restrepo, f. 812).

Con la república, en la Nueva Granada desaparece el rey, pero no así las ceremonias. La figura del monarca fue reemplazada por la Constitución y la

\footnotetext{
${ }^{8}$ Una excelente referencia al problema de la tensión y el conflicto entre el Estado nacional, lo étnico y las identidades está desarrollado en, Enrique Florescano, Memoria mexicana, México, Fondo de Cultura Económica, 2003.
} 
ascensión al trono se cambió por la posesión del gobernante. La ceremonias republicanas, al igual que durante la colonia, sirvieron entonces para legitimar a las nuevas autoridades y para enseñar a la población los valores del nuevo sistema. Así, cada texto constitucional durante la primera mitad del siglo XIX era publicado y jurado por medio de ceremonias que utilizaron la misma pompa barroca empleada durante el período colonial.

El 15 de mayo de 1832, en San Juan de Palmira se llevó a cabo la publicación y jura de la Constitución del Estado de la Nueva Granada en la cual los "becinos llenos de alborozo, an manifestado las congratulaciones de eterno reconocimiento, a sus dignos Representantes y prometen de nuevo sus servicios" (AGN, República, 29 d emayo de 1832, fs. 165).

De igual forma la ceremonia se repitió en varias provincias de la Nueva Granada; por ejemplo, el 22 de abril de 1832 en la ciudad de Santa Marta se llevó a cabo
... un convite general que se hizo a todos los vecinos, tanto por medio de un bando que ce les publico el día anterior para hacerles saber que se iba a publicar la nueva constitución dicha tarde para que asistiesen a tan Santo objeto, como también se hizo por medio de papeletas a los señores mas principales; y con repique de campanas, música, y multitud de tiros de fusil, se dio principio a dicha publicación, permitiéndoles a dichos vecinos toda clase de diversión, sin perjuicio de la moral pública por tres días y por la noche y iluminación; como en efecto así se ha verificado. Y al siguiente día [...] a las diez de la mañana en la puerta de la Santa iglesia se hizo el juramento de dicha constitución con los santos Evangelios, con la asistencia del señor cura (AGN, República, 29 de baril de 1832, fs. 150).

La plaza como espacio público, el repique de las campanas, la música y la misa aparecieron nuevamente como parte de la escenografía que identificaba la fiesta cívico-política de jura constitucional. Dos décadas después de la primera Constitución y de haberse iniciado el proceso de construcción de la nación, se seguían utilizando los mismos símbolos: ¿Quiere esto decir que nada había cambiado en el imaginario político?. Una respuesta negativa sería la más adecuada, pero ella no puede llevarnos a ignorar la introducción de algunos cambios.

La ceremonia de promulgación y jura de la Constitución de la Nueva Granada en 1832 muestra el surgimiento de nuevos actores, utilería y escenarios que han enriquecido el "teatro del poder". El 30 de abril de 1832, Marcelo Mendoza, secretario municipal de Riohacha, informaba a las autoridades y a la ciudadanía sobre la publicación y juramento de la carta constitucional, al tiempo que procedió a describir los sucesos de esos días. Por su importancia es necesario transcribir parte de ese informe ya que proporciona información que permite una reconstrucción del imaginario político de ese entonces.

En la mañana del 22 de septiembre de 1832, un ruido estruendoso llamó la atención de todos los riohacheros. Provenía de una salva de 21 cañonazos de artillería, del repique de las campanas de la iglesia, acompañada del zumbido de los cohetes. También, por la plaza principal marchaba una banda de músicos que anunciaban el recibimiento de la Constitución política de la Nueva 
Granada. Por la tarde del mismo día, la lectura de un bando anunció su publicación. El día anterior se había levantado en el centro de la plaza un templete, "sostenido por las seis columnas que representaban la justicia, la humanidad, el valor, la prudencia, la constancia, y la fidelidad, seis virtudes principales que resplandecen bajo el reinado de las leyes". En el centro del templete ondeaba el pabellón tricolor y adornaban la cornisa seis banderas con estas inscripciones: Nueva Granada, Venezuela, Páez, Santander, Márquez, Urdaneta.

A las tres de la tarde, la plaza estaba concurrida por las "personas más decentes de la ciudad, de un numeroso pueblo, y hermoseada por el bello sexo", que con los mas elegantes vestidos concurrió a tomar parte en el público regocijo. En medio de este numeroso público,

... el gobernador de la provincia se veía acompañado de todas las corporaciones, y de los ciudadanos mas notables. Colocando así su señoría en lo más alto del atrio del templete, dirigió al pueblo la palabra manifestando: que se iba a publicar la constitución del Estado, y que aquel acto augusto exigía una reverente atención. Enseguida se leyó la carta constitucional en alta voz.

Finalizada la publicación, el gobernador lanzó arengas al pueblo exhortando la defensa y respeto de la constitución (AR, abril 30 de 1832, fs. 479 - 480)..

En la noche del mismo día, hubo una fiesta y baile con una banda musical. Al siguiente día, se celebró la jura de la Constitución:

A las ocho de la mañana, las tropas de la guarnición se tendieron en las calles, desde el templete hasta la puerta de la iglesia, y el señor gobernador acompañado de las mismas corporaciones y de un lucido concurso, condujo la Constitución a la iglesia, recibiendo en el transito los honores militares.

Allí "El patriota Francisco Garavito", vicario eclesiástico, celebró el Santo sacrificio de la misa, "y pronunció una oración evangélica cuya sublimidad de conceptos dejó bien penetrados a sus feligreses de la obligación sagrada que iban a contraer, de obedecer, guardar y sostener la constitución política del Estado". Los feligreses hombres, mujeres, niños le escucharon con paciencia y respeto. Terminada la oración, "el señor gobernador subió al presbítero y presto el solemne juramento en la forma que espresa el decreto de la materia, y lo recibió en la misma forma a las corporaciones civiles". Concluida esta ceremonia, se cantó el Te Deum, el cual fue festejado lo mismo que la misa, con descargas de artillería y fusilería. Acabada la función de iglesia, se volvió a depositar la Constitución en el templete en el mismo orden y con los mismos honores. De allí se dirigió la comitiva a la casa de gobierno en la que estaba preparado un almuerzo. Los siguientes cinco días hubo iluminación y "regocijos públicos" (AR, 30 d ebaril de 1832, fs. $479-480)^{9}$..

\footnotetext{
${ }^{9}$ A renglón seguido aparece lo siguiente: “Comentario: Juramento de la Constitución de los hijos de Rio Hacha Abril 30 de 1832. "Concluido el acto se depositó la Constitución en el mismo templete, bajo un magnifico solio y una guardia con banderas que ya estaba prevenida le hizo los honores de ordenanza y cubrió con centinelas los costados y las gradas; retirándose la conjura por entre el alborozo de los vivas,
} 
Esta invaluable descripción nos ofrece un amplio panorama de las ceremonias republicanas. Al compararlo con la jura de fidelidad a Fernando VII del 11 de septiembre de 1808, vemos que se encuentran los mismos elementos y que de hecho, la ceremonia conserva gran parte de su ritualidad, el templete, el pabellón, la misa, la jura, El Te Deum, el baile, la iluminación y los días de fiesta. Pero algunas cosas cambiaron. Entonces aparecieron los "héroes" en la bandera y el objeto de la jura no era la persona del rey o su personificación en una cédula real, sino un texto, el cual era considerado un corpus: la Constitución. También se introdujo una nueva práctica, la lectura pública del texto constitucional. Sin embargo el imaginario utilizado para publicar la Constitución era similar al de 1811 y 1813 , el de la lealtad monárquica, ahora la republicana, en su forma tradicional.

La publicación era tan importante como la jura ya que aseguraba que la población conociera el texto constitucional. Por ello se recurrió a la fiesta como mecanismo para atraer a todos los ciudadanos incluidos mujeres y niños que según el relato anteriormente citado, salían a las calles a escuchar la lectura. Tanto valor político y social alcanzaron las constituciones que, por ejemplo, "un colombiano, ciudadano y propietario" que había sido expatriado por el gobierno español, luego de retornar a través de la villa de Barranquilla le suplicaba al vicepresidente de la República de Colombia, general Francisco de Paula Santander, le enviara "un ejemplar de la constitución [de 1821] que rija hoy en Colombia, pues no la he visto, y observo se cita con frecuencia" (Cortázar, 1966, p. 277).

Además de la lectura realizada en la plaza pública, ésta se repetía durante varias semanas en la misa dominical. Después de cada una de ellas el cura hacía una exhortación de la bondad del texto y recordaba el deber cristiano de obedecer. De tal manera que los rituales cívicos, políticos y religiosos que acompañaban las ceremonias de publicación y juramento fueron aprovechados para enseñar a los ciudadanos y feligreses los valores del nuevo texto, así como también sus deberes y derechos.

\section{Conclusión}

Aunque la propuesta de arraigar la figura de la constitución y del poder político de carácter republicano entre la población tuviese a grandes rasgos la misma caracterización formal que la anterior jura de los monarcas, se buscaba ahora conseguir el favor del pueblo hacia un nuevo orden político, así como la solidaridad hacia los nuevos gobernantes. En definitiva, a través de estas ceremonias se establecía el reconocimiento de la nueva estructura política con un nuevo depositario del poder elevado a la categoría de gobernante legítimo. Por lo tanto, con el advenimiento de la República, el depositario del poder, asume cabalmente su papel protagónico en la ceremonia. Lo que él dice y no lo que le dicen, es ahora el alma del ritual. La ceremonia es un puente que se tiende hacia delante, entre el poder y la historia (serrano, 1995, pp. XV-XVI).

salvas, música, y repique de campanas, á la casa del señor gobernador, en donde había preparado un esplendido refresco". 
El teatro del poder resulta ser fundamental para comprender el imaginario político, porque el poder se expresa y reafirma constantemente a través de escenarios donde se reproducen las jerarquías sociales. Con seguridad la imagen de la publicación y juramento quedaba guardada en la memoria de la gente que participaba de la fiesta cívica. Porque para las personas que vivieron la transición del período colonial a la república -y también para los que vivimos hoy- el poder estaba constituido sobre todo por símbolos. Sólo así se explica que los vecinos de la villa de Honda, después de haber observado que en la oficina de la gobernación que ahora ocupaba el general Antonio Obando, corría el mes de octubre de 1819- aun permanecían los retratos de los reyes Carlos IV y Fernando VII, exigieron que se retirasen por considerarlos una ofensa, pero además solicitaron la puesta en escena de un ritual público en el cual estuvieran representados los sentimientos de odio a los "tiranos" colgándolos de una horca y "permaneciendo allí nueve horas, y luego sean quemados a (los gritos de) viva el pueblo" (AGN, Anexo, 20 de octubre de 1819, fs. 197). Un hecho que tenía el carácter de un exorcismo político y la reafirmación de la tradición representada a través de las prácticas religiosas. En definitiva, era la manifestación de un conjuro político religioso que con el ritual de la quema de los retratos buscaba la purificación del nuevo régimen republicano.

\section{Bibliografía}

\section{Fuentes documentales}

Fondo Alonso Restrepo (manuscrito 562, fs. 812). Bogotá: Biblioteca Luis Ángel Arango (BLAA).

"Comunicación de José María de Lizarralde, interventor encargado de la administración de tabacos de Pore". (1808 2 de julio). En Anexo Historia (rollo 4, folio 387). Bogotá: Archivo General de la Nación (AGN).

Azevedo y Gomez, Joseph de. (1808). "Relación de lo que executo el M. I. C. Justicia y Regimiento de la M. N. y M. L. Ciudad de Santa fe de Bogotá, capital del Nuevo Reyno de Granada, para solemnizar el acto de la augusta proclamación que hizo dicha ciudad, del señor don Fernando VII por el rey de España e Indias, el día 11 de septiembre de 1808”. En Fondo Quijano Otero (317 (12). Bogotá: Biblioteca Nacional de Colombia (BNC).

Extraordinario de las Noticias Públicas de Cartagena de Indias (1810, 29 de Agosto). $\mathrm{N}^{\circ} 140$.

"Joaquín de Mosquera y Figueroa, presidente, Juan Villavicencio, Ignacio Rodríguez de Rivas, el conde de Abismal. Decreto en que se prescriben las solemnidades con que debe publicarse y jurarse la constitución política en todos los pueblos de la monarquía, y en los exercitos y armadas: Se manda hacer visita en cárceles con este motivo" (Cádiz, 1812, 18 de marzo). (Legajo 29, expediente 1). Madrid: Archivo del Congreso de los Diputados (ACDM).

"Juras constitucionales" (1813, 16 de abril). (Legajo 29, expediente 1). Madrid: Archivo del Congreso de los Diputados (ACDM). 
"Historia Representación del vecindario de Honda". (1819, 20 de octubre). Anexo (rollo 27, folio 197). Bogotá: Archivo General de la Nación.

"Elecciones". (1831, 24 de julio). Gaceta de Cartagena de Colombia, n 500.

"Juan José Donado, Santa Marta 29 de abril de 1832". (1832, 29 de abril). República, Fondo Gobernaciones. (rollo 388, fs. 150). Bogotá: Archivo General de la Nación.

"Titulo: Boletín Publicación y Juramento de la Constitución ". (1832, 30 de abril). Archivo Restrepo (AR) (folios 479 - 480)

"Esteban Martínez alcalde Parroquial y Pedro José Mesías alcalde $2^{\circ}$ de la parroquia de Tovo y Palmira". (1832, 29 de mayo). República, Fondo Gobernaciones. (rollo 388, fs. 165). Bogotá: Archivo General de la Nación.

Cochrane, Charles Stuart . (1994). Viajes por Colombia 1823 y 1824. Bogotá: Banco de la República.

Caballero, José María. (1974). Particularidades de Santafé. Un diario de José María Caballero. Medellín: Editorial Bedout.

\section{Fuentes bibliográficas}

Annino, Antonio. (1995). Voto, tierra, soberanía. Cádiz y los orígenes del municipalismo mexicano. En Guerra, François-Xavier (dir.), Revoluciones hispánicas. Independencias americanas y liberalismo español. Madrid: Editorial Complutense.

Backo, Bronislaw. (1991). Los imaginarios sociales. Memorias y esperanzas colectivas. Buenos Aires: Nueva Visión.

Corrales, Manuel Ezequiel. (1889). Efemérides y anales del Estado de Bolívar. Bogotá: Casa editora de J. J. Pérez.

Cortázar, Roberto. (1966). Correspondencia dirigida al General Santander. Bogotá: (s.e).

Demélas, Marie-Danielle. (s.f.). La invención política. Lima: Instituto de Estudios Peruanos.

Garavaglia, Juan Carlos. (2do semestre 1996). El teatro del poder: Ceremonias, tensiones y conflictos en el Estado colonial. Boletín del Instituto de Historia Argentina y americana Dr. Emilio Ravignani, No 14, pp. 7- 113.

Kantorowicz, Ernst H. (1985). Los dos cuerpos del rey. Madrid: Alianza Editorial.

Labelle, Micheline. Ideologie de couleur et classes sociales en Haïti, Montreal. Les presses de l'Université de Montréal, 1987. 
Mahan, Alfred. El interés de los Estados Unidos en el poderío marítimo, presente y futuro. Bogotá, Universidad Nacional de Colombia, sede San Andrés - Unilibros, 2000.

Martínez Garnica, Armando. (2005). La transición de un reino indiano de la Monarquía Hispánica a un estado republicano en las provincias neogranadinas (1810-1816). En Memorias del 2do modulo itinerante de la Cátedra de Historia de Iberoamérica. Independencia y transición a los estados nacionales en los países andinos: Nuevas perspectivas. (pp. 45 - 107). Bucaramanga: Universidad Industrial de Santander, Bucaramanga.

Millet, Allan. Historia militar de los Estados Unidos, por la defensa común. Madrid, Editorial San Martín, 1984.

Morelli, Federica. (2005). Territorio o nación. Reforma y disolución del espacio imperial en Ecuador, 1765-1830. Madrid: Centro de Estudios Políticos y Constitucionales.

Paschetta, Mario y Pedraza, Pedro. El apogeo de Napoleón. Barcelona, Biblioteca Recreativa, 1918.

Pattee, Ricardo. Haiti, pueblo afroantillano. Madrid, Ediciones Cultura Hispánica, 1956.

Pombo, Manuel Antonio y Guerra, José Joaquín. (1951). Constituciones de Colombia. Bogotá: Biblioteca Popular de Cultura Colombiana.

Powaski, Ronald. La Guerra Fría, Estados Unidos y la Unión Soviética, 1917 1991. Barcelona, Editorial Crítica, 2000.

Schama, Simón . (1990). Ciudadanos. Crónica de la Revolución Francesa Buenos Aires: Javier Vergara.

Serrano Migallón, Fernando. (1995). Toma de posesión: el ritual del poder. México: Porrúa.

Soler Torrijos, Giancarlo. A la sombra de los Estados Unido. México, Editorial Siglo XXI, 2002.

Thompson E. P. (1979). Tradición, revuelta y consciencia de clase, estudios sobre la crisis de la sociedad preindustrial. Barcelona: Crítica.

Recibido: 6 de junio de 2010.

Aprobado: 18 de noviembre de 2010. 
